\title{
Revista

«SOMOS UN PUEBLO, PRECISAMOS UN TERRITORIO PORQUE ALLÍ ES DONDE SE DA LA VIDA INDÍGENA; SIN TERRITORIO NO HAY IDENTIDAD COMO PUEBLO». BUEN VIVIR EN ARGENTINA

Morita Carrasco

Universidad de Buenos Aires carrascomorita@gmail.com

Silvina Ramírez Universidad de Buenos Aires y Universidad de Palermo silvina.ramirez@gmail.com

\section{RESUMEN}

El artículo aborda una perspectiva respecto del surgimiento de la noción del buen vivir, asociado a dos modelos de desarrollo en los países de Latinoamérica. Analiza las posibles consecuencias legales emanadas de la incorporación del respeto a la naturaleza en las constituciones de Bolivia y Ecuador. Desde una mirada interdisciplinaria que articula finalmente posiciones del derecho y la antropología, el artículo propone un análisis de algunos pronunciamientos y documentos de pueblos indígenas en la Argentina para comprender el sentido que estos dan al buen vivir, sin nombrarlo de este modo.

PALABRAS CLAVE: Argentina, pueblos indígenas, buen vivir.

«WE ARE A PEOPLE. WE NEED A TERRITORY BECAUSE THAT IS WHERE INDIGENOUS LIFE TAKES PLACE. WITHOUT A TERRITORY, THERE IS NO IDENTITY AS A PEOPLE». BUEN VIVIR IN ARGENTINA

\section{ABSTRACT}

This article views the emergence of the notion of good living (buen vivir), associated to development models in Latin American countries. It analyzes the possible legal consequences derived from the inclusion of the notion of respect for nature within the constitutions of Bolivia and Ecuador. From an interdisciplinary perspective that ultimately articulates positions drawn from law and anthropology, the article proposes an analysis of some statements and documents the indigenous peoples from Argentina have made in order to understand the meaning they place on the notion of good living, without naming it as such.

KEY WORDS: Argentina, indigenous peoples, good living/buen vivir. 


\section{INTRODUCCIÓN}

Respete la naturaleza. No tire basura RUTA N14-PROVINCIA DE ENTRE RÍOS-RA.

S umak kawsay (quechua), suma qamaña (aymara) o buen vivir es un llamado político; una propuesta de avanzada' para cambiar un modelo de desarroIlo que excluye a grandes contingentes de recursos humanos y destruye enormes cantidades de recursos no humanos indispensables para producirla.

Xavier Albó (2014) ha dicho, no hace mucho, que oyó por primera vez esta frase de boca de Simón Yampara cuando le aclaró a un enviado del Instituto de Desarrollo Internacional de Postdam (IDIP), Berlín, que los aymaras no hablan de 'progreso' sino de suma qamaña 'vivir bien', y que fue luego David Choquehuanca quién dinfudió ese concepto dentro y fuera de Bolivia y del continente: «Es (con) vivir bien todos, entre todos y con la madre tierra», dijo Choquehuanca.

Albó comenta que el enviado del IDIP estaba realizando un estudio sobre lo que se entiende por "progreso» en diversos países y en pueblos indígenas del llamado Tercer Mundo. Esto último permite comprender mejor cuál es el significado que comienza a enunciarse con el aporte de Yampara. En primer lugar, que progreso y suma qamaña son pares opuestos; que divergen respecto de los propósitos que persiguen. En este sentido, y en segundo lugar, es posible suponer que lo que hay detrás de este enunciado son dos modelos de vida social, dos proyectos políticos con sus respectivos discursos y prácticas asociados. El progreso se presenta vinculado a una cadena de significantes tales como desarrollo, modernidad, civilización. El buen vivir ¿con qué se asocia? De esta última pregunta nos ocuparemos en este artículo. De cómo conciben el buen vivir aquellos que defienden este modelo de vida en nuestro país es aún poco lo que podemos concluir puesto que, a diferencia de lo que ocurre en otras partes del continente americano, los indígenas en Argentina están comenzando a enunciar sus reivindicaciones desde el buen vivir, entendido como concepto filosófico, si bien como proyecto político ha estado siempre presente en sus formulaciones.

Previamente, nos ocuparemos de dar un panorama del contexto de surgimiento y producción de esta noción y sus efectos en la generación de transformaciones constitucionales en dos países de la región: Bolivia y Ecuador. En estos nuevos escenarios, en donde se cruzan saberes occidentales y saberes indígenas, deben señalarse las consecuencias jurídicas de su incorporación, para registrar

\footnotetext{
${ }^{1}$ Arturo Escobar (2013) vincula esta frase con lo que llama r-existencia.
} 
cuáles serían los eventuales impactos de respetar modelos de vida que se muestran como incompatibles con los modelos de desarrollo adoptados por nuestros países.

Asimismo, nos referiremos a la manera como fue definido el buen vivir, y a sus efectos legales en el enunciado de algunas constituciones, de respeto a la «naturaleza». Luego intentaremos desbrozar los significados que en la Argentina construyen los pueblos indígenas para comprender el sentido que estos dan al buen vivir, sin nombrarlo de ese modo.

\section{CONTEXTO DE SURGIMIENTO DE UNA NOCIÓN/PROYECTO POLÍTICO ALTERNATIVO AL MODELO DE DESARROLLO INSTALADO A NIVEL PLANETARIO CON EL AVANCE DEL CAPITALISMO}

Ante todo, es necesario recalcar que el buen vivir no es un concepto científico; no tiene pretensiones explicativas. Pero contiene descripciones sobre relaciones de los humanos entre sí y los recursos naturales. En tal sentido, dichas relaciones son fuente para el análisis de estudiosos de varias disciplinas. Por una parte, porque dan cuenta de los cambios que acontecen en la realidad. Así, algunos estudiosos podrán sentirse motivados a desbrozar los significados que las personas damos a estas palabras; otros, alentados por ello, se preocuparán por encontrar vías que den nueva legitimidad a esos sentidos.

En el escenario que transmiten estas descripciones, los bosques se destruyen, los suelos se contaminan, el agua comienza a escasear, entre otros problemas, por efecto de actividades humanas descontroladas. Esas actividades tienen como punto de partida la transformación de sistemas de explotación de los recursos naturales a escala planetaria por necesidades de la reproducción de una fase del capitalismo financiero internacional (Castoriadis 1991, Giarraca y Teubal 2008, Harvey 2005). Y ello impacta directamente en la vida humana y no humana; por tanto, conlleva riesgos que deben evitarse. He aquí el primer significado atribuido a estas descripciones: nuestras actividades nos destruyen pero está en nuestras manos revertir el avance del proceso destructivo. ¿Cómo? Aquí se nos presenta la pregunta acerca de qué relevancia dar a estos significados.

Puede pensarse que se trata de una visión de mundo en crisis y de un llamado, una invitación, a cambiarla por otra. Esta que implica un modo de vida destructivo por un modo de vida constructivo; que en contraste con el actual implicaría vivir bien. Desde su trabajo con comunidades afrodescendientes del Pacífico colombiano, Arturo Escobar se pregunta cómo podrían enfrentar la destrucción en 
el nivel ecológico para disminuir la pérdida de la biodiversidad y la deforestación; en lo social, para asegurar el respeto por sus derechos comunitarios; en el político, para proteger sus organizaciones y formas de gobierno propio; en lo cultural, para asegurar el ejercicio de sus identidades. Se trata entonces de mantener o recuperar «la capacidad de toda comunidad de definirse a sí misma, de fijar sus normas de existencia y convivencia, es decir, sus modos de r-existencia, y, en última instancia, de diseñarse a sí misma, en toda su diversidad y heterogeneidad y en su entramado con otros mundos» (Escobar 2013:33). En sus palabras, esta es la perspectiva de la ontología política.

El surgimiento del buen vivir como ideario nace, pues, de la articulación en disputa entre un modelo de desarrollo capitalista y los pueblos indígenas amenazados por el avance de la sobrexplotación de los recursos naturales que se encuentran en sus tierras y territorios. Ya hemos situado el núcleo descriptivo del que parte el buen vivir y el significado que acompaña a esa descripción; es en este sentido que lo llamamos ideario como un conjunto coherente de ideas y opiniones basadas en formas de entender el mundo y la vida.

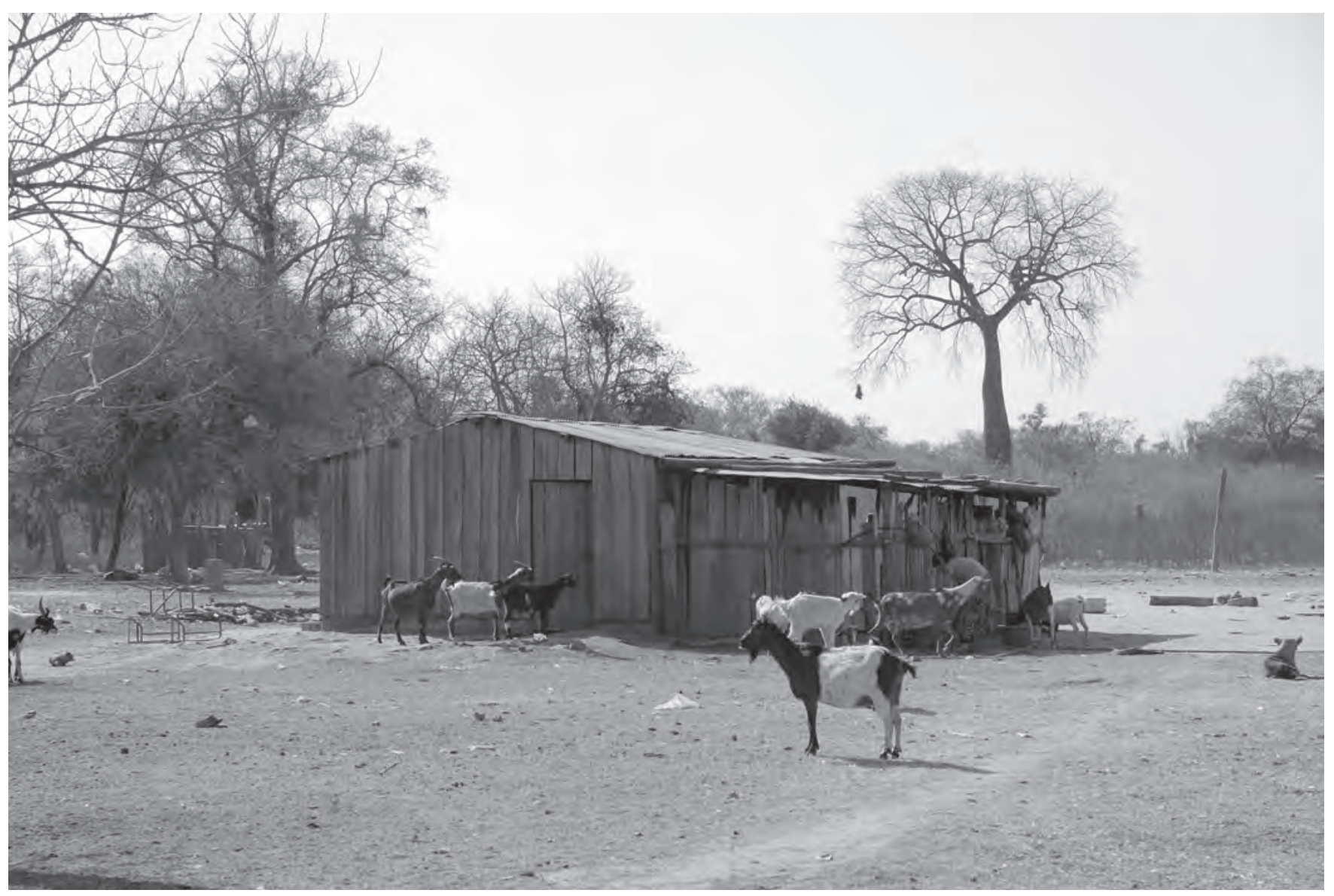


Si adoptamos la perspectiva de la ontología política planteada por Escobar (2013), este ideario está en la base de un proyecto político de transformación económico y sociocultural. La propuesta consistiría en adoptar otros puntos de vista, otros principios para cambiar nuestras formas de relacionarnos entre nosotros y los recursos de reproducción de la vida. En suma, se trata de introducir cambios en nuestras nociones de mundo conviviendo con otros en él. Procuraremos analizar este ideario como proyecto político tomando como atajo algunas ideas, proposiciones y nociones de mundo planteadas en Argentina por pueblos indígenas que no hablan de sumak kawsay y, sin embargo, comportan un ideario desde sus filosofías políticas que nutren holgadamente la perspectiva ontológica de la que habla Escobar.

Previamente, daremos un panorama acerca de la inclusión de este novedoso ideario en el derecho constitucional de dos países de América Latina, cuya población mayoritariamente indígena promueve su ampliación a toda la sociedad nacional, provocando fuertes tensiones con el modelo de desarrollo que traduce el capitalismo.

\section{LA NATURALEZA: UN NUEVO SUJETO DE DERECHOS}

Las discusiones suscitadas por la inclusión en la Constitución ecuatoriana de 2008 de dos artículos que reconocen a la naturaleza como sujeto de derechos colocan en el centro de la escena nuevos actores y nuevos problemas: pueblos indígenas, modelos de desarrollo, sistema capitalista, cosmovisión diferenciada del mundo, etc. En otras palabras, los derechos de la naturaleza nos obligan a repensar el lugar del ser humano en el contexto mundial y a reflexionar sobre la necesidad de «compartir el escenario» con otro sujeto, no humano, que instalaría lo que se ha dado en llamar «el giro biocéntrico» de la Constitución ecuatoriana (Ramírez 2011).

Los artículos 71 y 72, que incluyen estos nuevos derechos, instalan temas cuyas consecuencias jurídicas son dignas de ser analizadas. Sin lugar a dudas, los derechos de la naturaleza involucran numerosas perspectivas que deben tomarse en cuenta: elementos éticos, morales, políticos y jurídicos no pueden ser aislados, lo que exige de la mirada jurídica una especial atención.

Dichas perspectivas requieren, primordialmente, una tarea interdisciplinaria, que aúne no solo saberes indígenas y saberes occidentales, sino que dentro de estos últimos reúna las miradas de ecologistas, filósofos, economistas, antro- 
pólogos, abogados, politólogos, sociólogos, etc., que puedan complementar reflexiones, análisis, criterios para identificar los impactos que necesariamente traen aparejados estos nuevos derechos.

Del análisis de los artículos 71 y 72 de la Constitución ecuatoriana se derivan, en primer lugar, la incorporación — tal como lo expresa Gudynas (2010) — de nuevas concepciones temporales y territoriales. Así, pensar en milenios y en extensiones territoriales considerables, tener presente la existencia de ecosistemas, modifica sustancialmente la perspectiva utilizada y exige otra profundidad en la reflexión. Por otra parte, sostener también la existencia de ciclos vitales en lo tocante al espacio y al tiempo demanda una tarea interpretativa que excede la mirada del especialista jurista.

En segundo lugar, el análisis sobre el derecho a la restauración —y su diferencia o no con la reparación- significa ni más ni menos que pensar un sistema de representación diferente, porque es obvio que el ser humano seguirá teniendo un lugar central en el resguardo y la garantía de estos derechos contemplados. Si bien los abogados estamos habituados a trabajar con ficciones (basta pensar las sociedades anónimas, personerías jurídicas, etc.), los derechos de la naturaleza generan otro tipo de desafíos.

En tercer lugar, vale la pena señalar que la inclusión de la terminología «pachamama», como sinónimo del derecho a la naturaleza, establece claramente la intención del constituyente ecuatoriano de incorporar explícitamente la cosmovisión indígena. Sumado al sumak kawsay ya mencionado, la lectura que debe predominar es la presencia del intercambio de saberes indígenas y saberes occidentales, lo que al menos permite percibir la construcción de Estados interculturales. Tales Estados identifican la incorporación de «lo otro» como valioso, revalidando el estatus de los pueblos indígenas en la conformación del Estado.

Vale la pena también señalar que la Constitución boliviana, si bien incorpora (como lo hacen la generalidad de las latinoamericanas) derechos al medioambiente, no incluye específicamente a la naturaleza como sujeto de derechos. Sin embargo, en una legislación específica — la ley de la madre tierra- desarrollará estos conceptos, ${ }^{2}$ dotando a la madre tierra de una protección sólida, inconsistente con las acciones pergeñadas desde el gobierno para garantizar la obtención de ciertos recursos.

${ }^{2}$ Ley 300 del 15 de octubre de 2012, denominada «Ley marco de la madre tierra y desarrollo integral para vivir bien». 
Las contradicciones que se están dando en el plano de la realidad en Ecuador entre los derechos constitucionales y el modelo de desarrollo por el que se ha optado, se dan también en la dimensión normativa en Bolivia. Principalmente porque coloca en cabeza del Estado la explotación de los recursos naturales, considerando entonces que su apropiación -y consiguiente obtención de renta- debe ser incentivada. Estas contradicciones se están profundizando, gestando paradojas y desafíos para Estados que por un lado reconocen derechos indígenas, y simultáneamente los vulneran al optar por llevar adelante actividades extractivas.

Para entender cabalmente las discusiones que se están sosteniendo alrededor de estas nuevas categorías — que adquieren estatus jurídico, complejizando la interpretación de sus alcances y límites- es importante detenernos en algunas diferencias relevantes cuya raigambre se encuentra en debates iusfilosóficos que forman parte de cambios de paradigma, y que significan una nueva conceptualización de la relación humanos-naturaleza.

\section{JUSTICIA AMBIENTAL Y JUSTICIA ECOLÓGICA}

Es en los últimos años cuando ha tomado «carta de ciudadanía» la justicia ambiental. Habiéndose incorporado a la normativa vigente los derechos «de tercera generación», el respeto al medioambiente ha adquirido una importancia notable. Se discute mucho alrededor de la no contaminación, el cambio climático, la importancia de resguardar el hábitat, pero siempre enfocado desde la perspectiva del ser humano.

La justicia ambiental es deseable y requerida cuando se encuentran involucrados seres humanos, ya que dentro del marco axiológico predominante se considera imprescindible que para mejorar la calidad de vida del individuo, esta debe desarrollarse en un ambiente libre de contaminación, con condiciones mínimas que le permitan una existencia digna.

Las teorías de la justicia contemporáneas han sido construidas también alrededor de estas ideas. ${ }^{3}$ Las teorías liberales abonan la importancia de estos bienes, y también son sensibles a la protección del entorno, los animales, las plantas, pero no concebirían —ni podrían hacerlo, precisamente porque son antropocéntricas- que existan derechos independientes del ser humano.

\footnotetext{
${ }^{3}$ Basta citar a Rawls y su muy conocida Teoría de la Justicia (1979).
} 


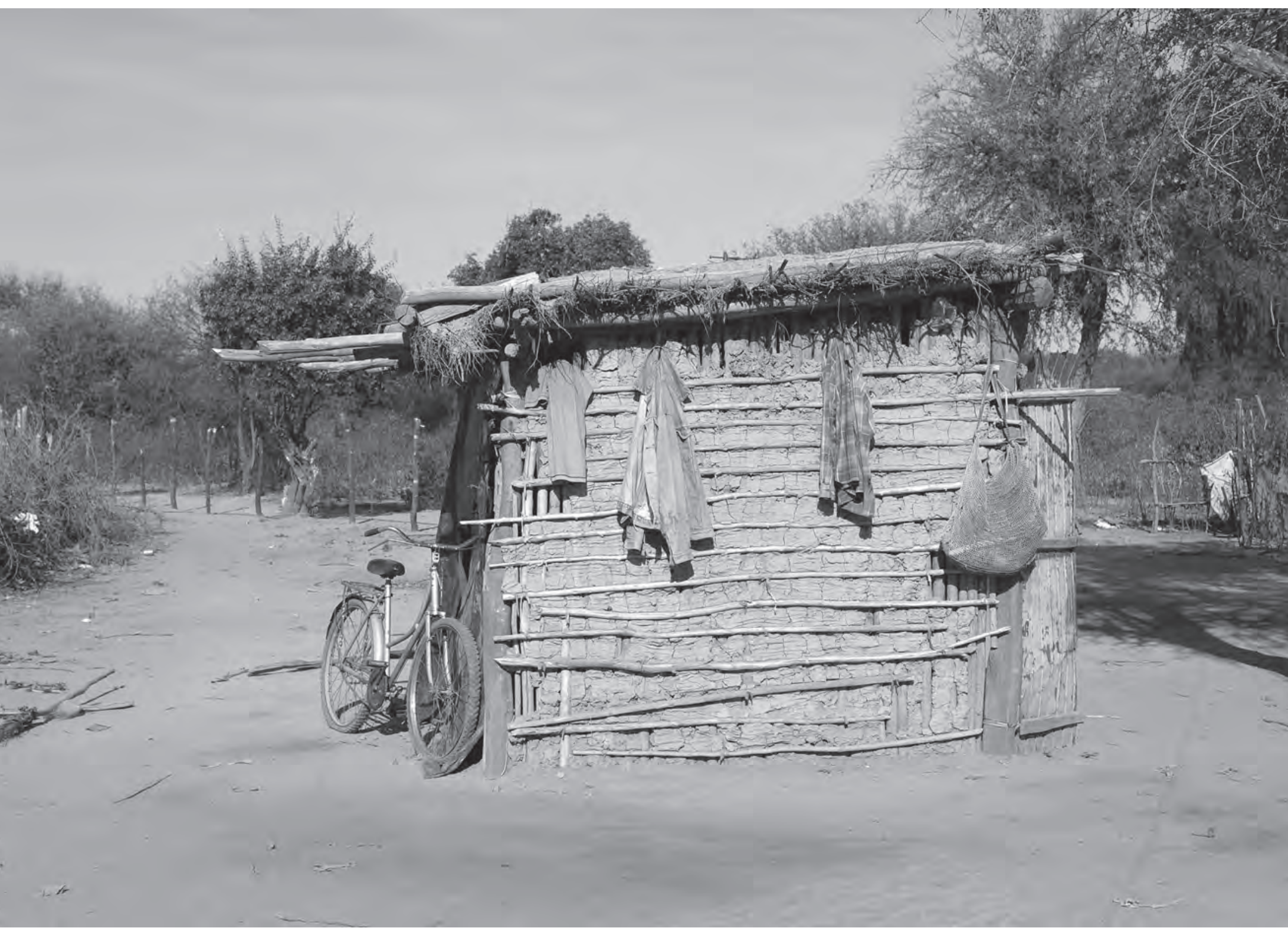

En otras palabras, la justicia ambiental debe complementarse con lo que se ha dado en Ilamar «la justicia ecológica». ¿En qué consiste esta justicia? Es aquella que se extiende a los demás seres vivos, independientemente de cuál sea su rol y relación con los seres humanos. Es así que ya no debe plantearse la pregunta: ¿mejora la calidad de vida de los seres humanos? Sino que el resto de las especies, y la naturaleza toda, tiene derechos más allá del individuo.

Esta idea de justicia ecológica presenta innumerables interrogantes. Vamos a intentar dejar planteados los más relevantes para este trabajo. Así, si bien se afirma que no solo los agentes morales son titulares de derecho, lo cierto es que el sujeto cognoscente es el ser humano, esa es una realidad insoslayable. 
Quienes escribimos este trabajo y llevamos adelante estas reflexiones somos seres humanos, y es imposible desprenderse de esa condición. Al parecer, eso nos llevaría a un razonamiento circular que siempre volvería al punto de partida, y allí precisamente está el desafío. Poder llevar adelante el ejercicio de conceder que la naturaleza tiene sujetos con independencia de nuestro propio bienestar.

Por otra parte, dado que somos ecosistemas en donde todos los seres vivos interaccionamos permanentemente, otro de los interrogantes que surgen se refiere al límite de la intervención tolerable. Gudynas (2010) hace mención de algunos criterios tales como mantener la calidad de vida, asegurar cierta calidad de vida, erradicar la pobreza sin caer en la opulencia. Si bien son criterios difíciles de identificar en la práctica, se presentan como un norte hacia el que debemos dirigir nuestras acciones. No se trata de que la naturaleza sea «intocada», sino más bien de garantizar que no será devastada, que las especies no estén condenadas a la extinción, que los desastres ecológicos no lleguen a ser inevitables.

Por el contrario, y en la vereda del frente de adscribir a posturas conservacionistas, no consideramos que no debamos comer una vaca, sino que lo relevante es que las vacas sigan existiendo como especie. De allí que se haga imprescindible un cambio de mirada.

Por último, la teoría también nos indica que es importante distinguir entre valores intrínsecos y valores instrumentales. Estos últimos emparentados con los mayores beneficios que la protección de la naturaleza produzca en los seres humanos. Por su parte, los valores intrínsecos representan una naturaleza valiosa más allá de la especie humana. En ese sentido, es relevante defenderla con independencia del bienestar que le ocasione al individuo.

Son la conjunción de valores intrínsecos y de valores instrumentales los que nos dan una idea acabada de un cambio de paradigma, que se va perfilando tímidamente, y que conceptos tales como buen vivir y derechos de la naturaleza van sugiriendo en los nuevos debates filosóficos.

\section{PROTECCIÓN VS. DESARROLLO}

Es notable cómo en Ecuador y Bolivia —con legislaciones claramente progresistas y protectoras de los derechos de los pueblos indígenas, lo que como también sucede en Argentina con una Constitución más austera en términos de inclusión de dichos derechos - asistimos a una dicotomía que se radicaliza con el correr del tiempo. Los derechos indígenas están contemplados normativamente, 
forman parte del derecho vigente, pero colisionan con lo que los gobiernos de los Estados entienden debe ser el desarrollo.

Así, se gestó una ecuación difícil de superar. Los países alegan la necesidad de explotación de recursos naturales para afrontar el despliegue de políticas sociales (salud, educación, vivienda) que garanticen un adecuado nivel de vida de la ciudadanía en general. Por su parte, esta explotación (que comprende petróleo, minerales, bosques, agua, etc.) viola claramente los derechos territoriales indígenas. En otras palabras, parece ser que la construcción discursiva es: «lamentablemente debemos pasar por alto los derechos indígenas para asegurar el bienestar de los habitantes, traducido en el goce de derechos económicos, sociales y culturales».

Para quebrar esta antinomia se hace preciso volver a dimensionar conceptos tales como buen vivir y derechos de la naturaleza, a su vez contrastarlos con los derechos que gozan los pueblos indígenas —al menos normativamente-y repensar el modelo de desarrollo para que las políticas asistenciales no sean parasitarias de un modelo que ancla su existencia en actividades extractivistas que dañan los territorios indígenas amenazando su identidad.

Por su parte, en Argentina, la vulneración de los derechos de los pueblos indígenas por medio de la explotación y los avances de las industrias extractivas es cada vez más profunda. A la explotación de petróleo se le suma la minería a cielo abierto, las industrias forestales y la ampliación de la frontera agropecuaria para la siembra de soya. De acuerdo con el Plan Estratégico Agropecuario que presentó el Poder Ejecutivo en 2011, se prevé en los próximos diez años un incremento de $27 \%$ de la superficie para siembra, ${ }^{4}$ lo que significa más desmonte y avance sobre el territorio reclamado por las comunidades y los pueblos indígenas (Ramírez 2012).

En este escenario político la batalla jurídica es muy compleja. Se cuenta con las herramientas jurídicas para demandar la protección de los derechos de los pueblos indígenas, pero las decisiones políticas ya están tomadas. Con este punto de partida la confrontación es muy desigual. Sin embargo, dentro de esta realidad es imprescindible tejer alianzas con diferentes sectores que puedan revertir algunas de las decisiones tomadas hasta el presente.

Si pensamos que existen, a la par de los movimientos indígenas, sectores ambientalistas dispuestos a acompañar el reclamo, podemos imaginar futuros y po-

${ }^{4}$ Ceppas/Gajat, «Plan Estratégico Alimentario vs. Derecho al acceso a la tierra de familias campesinas y comunidades indígenas», Buenos Aires, noviembre de 2011. 
tenciales escenarios en donde se equiparen los campos en disputa. Y en donde, en definitiva, se llegue a cuestionar el modelo de desarrollo imperante.

La presencia de los movimientos indígenas en la protección de los bienes comunes naturales viene de la mano de la defensa de sus territorios. Cabe citar acá entre otros la lucha del pueblo wichí en contra de los desmontes y la tala ilegal de madera de bosques nativos, la lucha contra las petroleras en la provincia de Neuquén que desde hace más de una década lleva adelante el pueblo mapuche, o la resistencia del pueblo kolla a la exploración de mineras en busca de litio en la provincia de Jujuy y las reiteradas manifestaciones en contra de la competencia mundial del Rally Dakar. ${ }^{5}$

Si bien el concepto de «naturaleza como sujeto de derechos» es una categoría reciente desde hace un tiempo el movimiento indígena está instalando con mayor fuerza la idea del buen vivir. En este sentido, es interesante mencionar la Primera Marcha de Mujeres Originarias por el Buen Vivir realizada en 2014 en la provincia de Chubut, y la propuesta de creación de un consejo de mujeres originarias con iniciativa parlamentaria en el Congreso de la Nación para que se inicie un proceso de consulta sobre el buen vivir. Desde su propia mirada y definición, afirman:

El buen vivir, dentro de la cosmovisión originaria, es el paradigma del equilibrio entre el ser humano y su entorno, la satisfacción de nuestras necesidades, buscando la sana relación socio-económica, sostenible, contraria al capitalismo devastador, entendiendo de que todo lo que existe es parte del equilibrio y la armonía con la vida; las comunidades indígenas, los ciudadanos, los territorios, la naturaleza y el Estado.

Este concepto se plantea como herramienta de discusión y exigencia de los derechos para las comunidades indígenas, que pugnan constantemente, en sus territorios, contra la explotación salvaje como la extracción minera, la agronomía intensiva y explotación turística indiscriminada.

Las mujeres originarias se reúnen para revivir un modelo que implica e invita a todos los habitantes de Argentina para participar en la búsqueda del equilibrio entre la mujer y el hombre con su entorno; desde las visiones, experiencias, voces, propuestas, herencias ancestrales y diversidad de las mujeres participantes. En Chubut se gestará y dará vida al buen vivir para todo el territorio argentino. ${ }^{6}$

\footnotetext{
${ }^{5}$ Más información en <http://argentina.indymedia.org/features/pueblos/>.

${ }^{6}$ Crónica del Encuentro de mujeres originarias por el Buen vivir en <http://www.agenciawalsh. org/po-/88-pueblos-originarios/13069-epuyen-chubut.html>.
} 


\section{FILOSOFÍA Y POLÍTICA INDÍGENA DEL BUEN VIVIR EN LA ARGENTINA}

Actualmente en la Argentina la población indígena está representada por 32 pueblos reconocidos por el Estado, con 955032 personas que se declaran pertenecientes o descendientes de un pueblo indígena, de una población general de 40117096 personas.?

La toma de conciencia sobre la presencia viva de los indígenas es un asunto relativamente novedoso en un país que se piensa a sí mismo y se presenta ante la comunidad internacional como un producto de la inmigración europea fomentada por intelectuales y élites nacionales desde los años inmediatamente posteriores a la independencia de España (1810). Durante 104 años, hasta la reforma constitucional de 1994, este argumento avaló el desconocimiento de la existencia de población originaria. De ese modo se justificó una empresa de aniquilamiento primero, para intentar «limpiar» el territorio de sus primigenios ocupantes, y luego impuso una política de asimilación colonial. Sus tierras y fuerza de trabajo fueron los recursos ambicionados por quienes gobernaban: al sur del país aquellas eran requeridas para el asiento de una oligarquía agrícola-ganadera que crearía grandes latifundios desplazando hacia los márgenes los restos de pueblos debilitados por la ocupación y la guerra. Al norte, los brazos fuertes de grupos de indígenas, móviles y dispersos en numerosos sitios, eran imprescindibles para poner en marcha una incipiente, aunque prometedora, industria extractiva para capitales extranjeros. Así, desde el comienzo los intereses económicos prevalecieron en la administración de una ciudadanía indígena que favoreciera dichos intereses (Carrasco 2014).

Hacia el último cuarto del siglo XIX ya se considera finalizado el avance de las fronteras y el sometimiento de los indígenas. Entre 1879 y 1885, las sucesivas campañas denominadas globalmente «Conquista del desierto» logran desarticular la resistencia militar de los pueblos indígenas de Pampa y Patagonia. Y a partir de 1885 la preocupación es la radicación de los pueblos indígenas en reservas,

\footnotetext{
${ }^{7}$ Datos del censo General de Población y Viviendas del año 2010. La cantidad de población es motivo de controversia entre los pueblos indígenas y el Estado. En los años 2004 y 2005 se llevó a cabo una Encuesta Complementaria Indígena (ECI) para conocer la cantidad de personas que se reconocían pertenecientes o descendientes de un pueblo indígena. Las organizaciones indígenas y varias ONG objetaron la metodología aplicada y consideraron que el total de la población había sido subestimado. En su opinión el número de personas indígenas actualmente en el país sería superior a 1800000 . Sobre la Encuesta Complementaria se puede consultar el sitio oficial <http:// www.indec.mecon.ar/webcenso/ecpi/index_ecpi.asp>.
} 
colonias agrícolas y pastoriles, administradas por el Estado o las misiones religiosas. Obtenido ya el recurso tierra y apropiados los territorios, la fuerza laboral indígena constituye nuevamente el recurso a privilegiar. A partir de la década del cuarenta, la «integración» de los indígenas, más que su «colocación», comienza a ser el propósito que orienta la política estatal. Tales medidas de disciplina y control no lograron aquietar la capacidad de lucha de estos pueblos en defensa de sus territorios, sus formas de vida, sus autoridades, sus visiones de mundo. Desde los primeros contactos con los colonizadores se involucraron en la pelea por conseguir reformas legales ${ }^{8}$ que contienen ricas expresiones de su forma de entender el mundo.

Hacia finales del siglo xx se concentraron en la elaboración de propuestas legislativas para cambiar la relación entre ellos y el Estado a nivel provincial y nacional (Carrasco 2000 y 2002). A partir de la década de los noventa tuvo lugar una intensa movilización indígena. Un hito de sus actividades fue lograr la inclusión en la Constitución nacional de sus derechos como pueblo.9 Tomaremos aquí algunos de los pronunciamientos que se hicieron en dos momentos históricos, a finales del siglo xx y primera década del siglo XxI. Estas fechas coinciden con el inicio de la organización panindígena surgida en la provincia de Formosa (19801981), que logró incorporar a los pueblos como sujetos de derechos específicos (Ley 426/84) y se constituyó en el antecedente principal que llevó adelante la inclusión de estos derechos en la Constitución nacional (1994). Ambos procesos de política indígena se continuarán en los años siguientes en dos frentes organizativos, cada uno con su particularidad: uno nacional (Programa de Participación Indígena), impulsado por quienes formaron parte de la movilización en Formosa; y otro regional (Foro Patagónico), respaldado por organizaciones del pueblo mapuche. Apoyado por el grupo católico de base que trabajara con los indígenas en Formosa, y con recursos del Estado nacional, el primero de estos frentes pensaba que era posible reunir a todos los pueblos en un solo movimiento para lle-

${ }^{8}$ En 1875, luego de la Batalla de Quera los kolla, en reclamo de sus tierras, que habían sido entregadas a un terrateniente, exigieron su devolución firmando el documento como "pueblo indio».

${ }^{9}$ «Son atribuciones del Congreso: Reconocer la preexistencia étnica y cultural de los pueblos indígenas argentinos. Garantizar el respeto a su identidad y el derecho a una educación bilingüe e intercultural; reconocer la personería jurídica de sus comunidades, la posesión y propiedad comunitaria de las tierras que tradicionalmente ocupan; regular la entrega de otras aptas y suficientes para el desarrollo humano; ninguna de ellas será enajenable, transmisible ni susceptible de gravámenes o embargo. Asegurar su participación en la gestión referida a sus recursos naturales y a los demás intereses que los afecten. Las provincias pueden ejercer concurrentemente estas atribuciones». 
var adelante sus reivindicaciones; desde una trayectoria de dirigentes formados en parte en arenas internacionales, el segundo, con aportes del Banco Mundial, buscaba consolidar fuerzas internas en un ámbito espacial menos ambicioso, mejor conocido y más fácil de manejar. Algunas anotaciones más pueden ayudar a comprender el porqué de estos dos frentes. Por un lado, la búsqueda de un interlocutor nacional se hacía imperiosa dado que hasta entonces y aún en nuestros días, no existe en Argentina una organización nacional como sí la hay en Bolivia, Colombia, Ecuador, entre otros países. Por el otro, en la época en que se gestan estos movimientos había en el país 18 pueblos. Y un tercer elemento es la ideología que acompaña a los dos grupos de participantes: el primero estaba conformado por referentes, dirigentes, jefes de comunidades locales con un pequeño agregado de representantes de organizaciones con asesoramiento jurídico del Equipo de la Pastoral Aborigen; el segundo estaba conformado por representantes de organizaciones que buscaban su autonomía y rechazaban el asesoramiento externo.

\section{NOCIONES Y PLANTEAMIENTOS POLÍTICOS DE LOS PUEBLOS INDÍGENAS EN DOS MOMENTOS}

Entre 1996 y 1997, comunidades de base de varios pueblos y algunas organizaciones llevaron adelante un proceso de elaboración de principios y propuestas legislativas cuyos resultados se plasmaron en el documento del Foro Nacional del Programa de Participación de Pueblos Indígenas. ${ }^{10}$ El Foro Indígena Patagónico convocado por la Coordinación de Organizaciones Mapuche Taiñ KiñeGetuam reunió a representantes de los Pueblos Originarios Mapuche Tehuelche y Selk'nam en la región sur del país. Tomaremos algunos de sus pronunciamientos para intentar aproximarnos al ideario planteado por la dirigencia de lo que podríamos considerar, desde su perspectiva, qué es buen vivir." Luego los contrastaremos con otros planteamientos indígenas realizados casi 20 años más tarde.

\footnotetext{
${ }^{10}$ El PPI fue un movimiento social de características multiétnicas. Si bien en la elaboración de los documentos finales la voz es la de los indígenas, en las reuniones participaron asesores, equipos de apoyo, ONG, amigos, colaboradores. Todos compartían las deliberaciones de los grupos de trabajo, opinando y realizando tareas de secretaría. En la plenaria, en cambio, por decisión de los coordinadores indígenas, la participación de no indígenas se limitó a observar y escuchar sin emitir juicios $u$ opiniones, salvo requerimiento expreso.

${ }^{11}$ En Argentina, a pesar de la multiplicidad de pueblos indígenas existentes, se seleccionó para este trabajo en el primer tramo comparativo a aquellos que habitan la Patagonia, fundamentalmente por su grado de organización. Si bien después de 20 años las circunstancias han ido cambiando
} 


\section{FORO NACIONAL DEL PPI}

Brevemente, el documento enarbola tres principios fundamentales: subjetividad - territorialidad - comunitarismo.

Es de recordar que la década de los noventa se desenvuelve en el contexto macroeconómico y social del neoliberalismo, que implica la centralidad del mercado como regulador no solo de la economía (privatización de los bienes colectivos, descentralización de los servicios sociales básicos como salud, educación, etc.), sino también de las conductas sociales ahora centradas en la responsabilidad individual por su cuidado. El periodo se caracterizó por una disminución del papel del Estado supuestamente para conseguir eficiencia en la provisión de los servicios y abrir las fronteras del capital transnacional (Sieder 2004). Es en este marco económico-político de transformaciones que resulta pertinente conocer las aspiraciones y demandas indígenas esbozadas en el PPI, y preguntarse por el carácter de estas atendiendo a los principios en que se sustentan.

El documento contiene un capítulo de fundamentos generales, uno de propuestas y un tercero de recomendaciones. En los fundamentos se representa la relación entre pueblo indígena y Estado. Primero como una cultura diferente con un modo propio de pensar, sentir y hacer (en Carrasco 2000:265). Más adelante se describe del modo siguiente:

Tenemos como fundamentos principales la convivencia pacífica y social, con nuestro entorno natural (cosmos). Este respeto está basado en la concepción de que todo lo que nos rodea es sagrado y por lo tanto nosotros somos naturaleza y espiritualidad.

Nuestro tesoro cultural contiene creencias costumbres conocimientos, valores, técnicas, formas de ver, sentir, pensar, crear, expresar esperanzas, sueños... Tenemos como ámbito geográfico el territorio que son los cerros, ríos, laguna, bosques, cielo, sol, luna, etc., es el entorno donde viven nuestros dioses y los espíritus de nuestros ancestros que siempre nos acompañan como símbolo del fuego sagrado, de la paz y de la vida. El espacio natural, social y espiritual ha determinado la elección de nuestros nombres personales originarios en presencia directa con el medio ambiente. También ha determinado nuestros lugares y formas de comunicarnos armoniosamente (Carrasco 2000:264).

y no solo la Confederación mapuche se destaca como referente organizacional indígena, en 1997 sobresalían por su consistencia y por la formación de sus líderes. 
He aquí uno de esos principios que, al decir de Arturo Escobar, constituyen una política ontológica. Es decir: una toma de posición del sujeto anclada en una visión de mundo y del propio ser; más aún, una «afirmación y reafirmación del ser» (Escobar 2013:15). A la vez un sujeto diferente que por razones históricas ha sido enajenado por «imposición de una cultural [...] basada en el individualismo, el egocentrismo, la codicia, la soberbia y el racismo» (Carrasco 2000:264).

Diferencia cifrada en el reconocimiento de derechos como colectivo: «Nuestras comunidades, continuando el camino de recuperación de sus organizaciones ancestrales, reivindican, desde el derecho de los pueblos indígenas, el derecho a su identidad y a la autoafirmación» (Carrasco 2000:263).

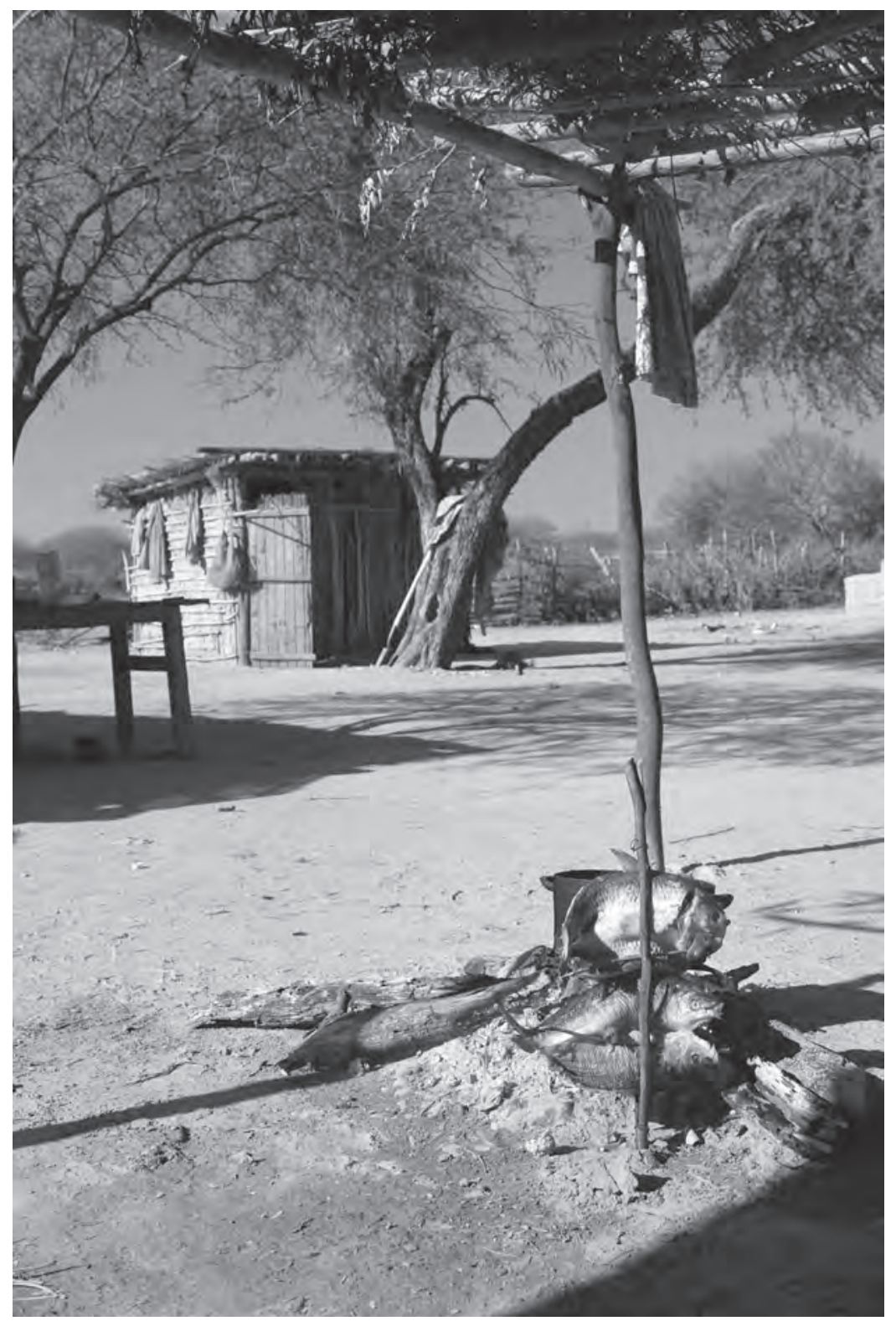


Desde estos principios en el mismo capítulo se incorporan sus principales demandas: «Territorio, pueblo y derechos comunitarios son los principios y fundamentos básicos del pensamiento y sentimiento del pueblo indígena» (Carrasco 2000:268). Se reafirma el respeto de la naturaleza, su biodiversidad «porque vivimos en contacto con ella, somos uno más de sus componentes». Es en función de esta relación que las «comunidades entendemos por proyecto de desarrollo al conjunto de acciones concretas llevadas a cabo por las comunidades para satisfacer sus necesidades, aprovechando las posibilidad que ofrece el territorio indígena, procurando no alterar el equilibrio que reina en él» (Carrasco 2000:272).

El capítulo de Propuestas y el de Recomendaciones hacen demandas también vinculadas al contexto neoliberal en que tuvo lugar el PPI. Con todo, una lectura atenta rescata el ideario de la ontología política, centrada en el sujeto pueblo y en el territorio como espacio donde conducir su proyecto político en libertad, de acuerdo con su visión de mundo y relación entre todos los seres: «Territorio, pueblo y derechos comunitarios son los principios y fundamentos básicos del pensamiento y sentimiento del pueblo indígena. Disminuir la fuerza de uno de ellos significa inmediatamente debilitar a los otros. Hay que destacar que la forma en que las comunidades de los Pueblos Indígenas ocupan o ejercen la posesión sobre sus territorios y tierras es diferente de los no indígenas» (Carrasco 2000, subrayado nuestro).

\section{FORO INDÍGENA PATAGÓNICO}

Realizado en la provincia de La Pampa los días 12 a 14 de diciembre de 1997..2 Para facilitar el debate, los participantes se distribuyeron por grupo en cinco comisiones, en torno a los principales derechos reconocidos en el artículo constitucional: 1) «reconocer la preexistencia étnica y cultural de los pueblos indígenas argentinos y garantizar el respeto a su identidad»; 2) alcances del «derecho a una educación bilingüe e intercultural [...] reconocer la personería jurídica de sus

12 Durante 1997 y en el marco de un programa de capacitación de indígenas en la producción de proyectos de desarrollo financiado por el Banco Mundial, los coordinadores indígenas de la región sur (miembros de la Coordinación de Organizaciones Mapuche Taiñ KiñeGetuam) tuvieron la iniciativa de aprovechar la ocasión para conformar un foro de debate con los representantes de organizaciones y comunidades de los pueblos mapuche, Tehuelche y Selk'nam/Ona. El propósito fijado fue el de discutir y definir la posición de estos pueblos frente a la pendiente reglamentación del artículo 75, inciso 17 de la Constitución Nacional, dando así cabida a la opinión de algunos dirigentes y representantes que, por distintas razones, no habían participado del PPI (Briones y Carrasco 2003). 
comunidades», 3) personería jurídica ${ }^{13}$ como instrumento de organización para los indígenas y como instrumento de control desde el Estado; 4) «la posesión y propiedad comunitaria»; 5) «asegurar su participación en la gestión referida a sus recursos naturales y a los demás intereses que los afecten». ${ }^{14}$

Pueblo, autonomía y territorio son las nociones que concentraron el trabajo de las comisiones con el propósito de favorecer ciertas interpretaciones y excluir otras, así como de investirlos de connotaciones propiamente indígenas.

El punto de partida del documento es, como en el Foro Nacional, la afirmación del ser del pueblo desde su visión de mundo. «Todas las fuerzas/poderes/vidas —Kom, Pu Newén — de nuestro entorno natural — Waj Mapu— nos dieron su claridad y energía para comprometernos junto a ellos en la protección de nuestros territorios que es la defensa de la vida misma, nuestra y del planeta» (Carrasco 2000:305).

Ya desde la presentación de las comisiones de trabajo se instala una fuerte orientación filosófica mapuche legitimada por las autoridades políticas — Lonko_, las autoridades filosóficas religiosas —Pillán Kuse—y el mensajero del rakizuam —werkén- que guiarán las discusiones «por ser los depositarios históricos del conocimiento y el derecho mapuche» (Carrasco 2000:309) y porque son quienes orientan sobre «qué queremos como sociedad para los tiempos por venir» (Carrasco 2000:309).

Autoridades originarias, filosofía y derecho propios requieren un «lugar geográfico donde nos reunimos a debatir, que es el histórico territorio mapuche [...]» (Carrasco 2000:309).

Pueblo, territorio y autonomía son los tres pilares que deben quedar condensados en un Estatuto de Autonomía Indígena donde se reconozcan los derechos fundamentales que se debatieron en el Foro:

[...] reconocimiento a un autogobierno a través de nuestras estructuras de autoridades originarias, reconocimiento de nuestros principios y normas jurídicas: Nor Az Mogen, control de los recursos naturales y de nuestra biodiversidad ixofil mogen redistribución territorial que permita la restitución histórica con dignidad (Carrasco 2000:321).

Mapu (tierra) [...] es el lugar donde se encuentran y conviven PuNewen las fuerzas que componen la naturaleza y la sociedad integrante de los pueblos originarios, es el

${ }^{13}$ Se planteó el interrogante: ¿como instrumento de organización para los indígenas o como instrumento de control desde el Estado?

${ }^{14}$ Se puede consultar el documento completo en Carrasco (2000:304-329). 
lugar donde conviven el Gen del Ko del Mawisa del Kurufy todas las demás vidas del universo

Wallmapu (territorio mapuche) se refiere al concepto de visión del mundo mapuche. Todo lo que la vista alcanza a ver, como nuestros mayores lo representaron en el Kulxun. Allí se engloba todo el contenido de la Mapu; Minche Mapu, Mapu, Wenu Mapu, Lafken Mapu. Así explicamos el ordenamiento y el equilibrio de estas fuerzas. Los poderes o Newen se complementan, se equilibran, se interrelacionan entre sí. Cada newen tiene su rol y es responsable del equilibrio del Wallmapu (Carrasco 2000: 323).

Como en el Foro Nacional también en este se marcan las diferencias con la sociedad estatal que «impuso un nuevo principio, un nuevo orden. Un orden donde el hombre es el centro y la naturaleza es algo que puede dominar, que está a su servicio, con el objeto de lucrar» (Carrasco 2000:310).

Esta dominación política se sostiene un su [del Estado] sistema jurídico que no es otra cosa que un conjunto de ideas que responden a otra concepción cultural, a otro sistema de vida. Este orden jurídico y su conjunto de leyes permiten el robo y la explotación de nuestros recursos naturales (Carrasco 2000:311).

Sintetizando, de la lectura de ambos documentos resalta la demanda de ejercicio del derecho a ser diferentes, sustentado en principios que confrontan la identidad indígena con la universalidad de la identidad del ciudadano del Estadonación. El territorio como espacio de libertad donde reproducir el sentido de ser un pueblo desde la guía que impulsan autoridades y líderes históricos.

Y de modelar su futuro de acuerdo con una visión de mundo que contempla la unidad de todos los seres vivos.

\section{CONSEJO PLURINACIONAL INDÍGENA, PRONUNCIAMIENTO CASI 20 AÑOS MÁS TARDE}

Unos meses antes de las celebraciones oficiales por el Bicentenario de la Patria (mayo 2010) varias organizaciones marcharon desde las regiones del noroeste, noreste y Patagonia hasta la ciudad de Buenos Aires. Allí, frente a la casa del gobierno hicieron público su reclamo: territorio, respeto a sus culturas y justicia. La tierra robada será recuperada clamaron. Denunciaron la presión y el desalojo que sufren por causa de empresas extractivas (mineras, agropecuarias, petroleras) y la 
complicidad del gobierno que no les pone límites. Por el contrario, la presidenta (Cristina Fernández de Kirchner) en una entrevista privada con algunos dirigentes les aclaró que en caso de existir petróleo en tierras comunitarias se daría prioridad a la explotación.

En su documento «Derechos Humanos para los Pueblos Originarios» dirigido a la presidenta expresaron:

Nunca habíamos tenido tantos derechos reconocidos en normas nacionales, instrumentos internacionales ratificados por el Estado. Sin embargo vivimos una alarmante etapa de negación y exclusión. Nuestra realidad es un tema de derechos humanos. Sin embargo, la relación que propone el Estado con los pueblos indígenas es sólo desde un enfoque de pobreza. Nos visibilizan sólo como objeto de asistencia o de planes de emergencia, cuando somos sujetos de derechos políticos (Aranda 2013).

El contexto económico-político no es el mismo. En varios países de América Latina una nueva clase de dirigentes enrolados en una «nueva izquierda» ha ganado su ascenso al gobierno (Argentina, Bolivia, Brasil, Chile, Ecuador, Perú, Uruguay, Venezuela), ${ }^{15}$ desde el cual llevan adelante discursos y prácticas políticas que avanzan en transformaciones sustanciales en sus sociedades, ampliando derechos civiles a grupos/personas discriminados. Sin duda presentan diferencias entre ellos pero tienen en común posiciones críticas sobre el reduccionismo del mercado neoliberal y «postulan la lucha contra la pobreza como una de sus tareas prioritarias» (Gudynas 2009:190). Pero, paradójicamente, en lo que respecta a sus políticas económicas — con más o menos diferencia— no se distancian demasiado del modelo de desarrollo extractivista. Más aún, el extractivismo contemporáneo se profundiza, en alguno de esos países; sobre todo en los sectores minero y de hidrocarburos, a la vez que se ha dado fuerte aliento a la transformación agrícola para la producción de monocultivos de exportación, como el de la soya.

La otra cara trágica del modelo de desarrollo extractivista, o «mal desarrollo» como prefiere Ilamarlo Gudynas (2011), es que produce contaminación ambiental, desplazamientos de poblaciones, expoliación de recursos naturales no renovables, destrucción de las economías regionales y, paralelamente, bajos niveles de desarrollo humano. Para hacer frente a los altos índices de pobreza y las limitaciones en el acceso a la alimentación y a otros servicios básicos, los gobiernos progresistas despliegan políticas asistenciales en forma de subsidios monetarios

\footnotetext{
${ }^{15}$ Mayor información puede consultarse en Gudynas (2009).
} 
bajo distintos rubros, ${ }^{16}$ produciendo masas de clientes cautivos para asegurar la gobernabilidad del partido en el poder. ${ }^{17}$

Simplemente, y a modo de ejemplo, desde la sanción de la Ley Nacional de Protección de los Bosques Nativos (26331 en 2007) en la provincia de Salta se deforestaron 350000 hectáreas de las cuales 100000 estaban protegidas por la ley. Un reciente informe de Greenpeace advierte que la provincia pretende cuadruplicar su reserva ganadera para 2030, lo que resultará en nuevos desmontes de hasta tres millones de hectáreas (Greenpeace 2013). En la localidad de Ballivian, donde ya se han desmontado más de 90000 hectáreas, las comunidades indígenas sobrellevan una vida sin agua, sin alimentación y sin servicios sanitarios, literalmente encerradas por la deforestación. ${ }^{18}$

Luego de la «histórica» marcha de los pueblos originarios en el bicentenario de la patria, se crea el Consejo Plurinacional Indígena. Unos años más tarde, en 2013, el Consejo convoca a una Cumbre de Pueblos Indígenas en la provincia de Formosa para dar a conocer la situación por la que están atravesando: persecución, procesamiento de dirigentes, demora en la implementación de los derechos territoriales, ${ }^{19}$ aumento del número de muertos por desnutrición, contaminación de tierras y aguas por empresas petroleras y fumigaciones con agrotóxicos.

En abril de 2014, reunido en la provincia de Neuquén, el Consejo Plurinacional Indígena emite un Pronunciamiento. Hace un llamado a «amplios sectores preocupados por la salud de nuestra madre naturaleza» (negritas nuestras); destaca algunos logros obtenidos por la lucha indígena; advierte que las comunidades se mantienen en alerta y movilizadas «por los planes de explotación que se anun-

${ }^{16}$ En Argentina existen numerosos planes para atender las necesidades de: 1) madre de siete hijos; 2) asignación universal por hijo menor de 18 años; 3) discapacidad; 4) plan nacer 5) viuda; 6) plan remediar, entre otros.

17 Gudynas Ilama «trampa asistencialista» a esta política (2011:194).

${ }^{18}$ Véase información en El Nuevo Diario de Salta, Argentina <http://www.nuevodiariodesalta. com.ar/noticias/1131/impulsan-un-desmonte-que-condenaria-las-comunidade.html>.

${ }^{19}$ En 2006 se promulgó la ley 26160 de Emergencia de la Propiedad Comunitaria. Esta prevé la suspensión de los desalojos judiciales por cuatro años y la realización de relevamientos de las tierras de «ocupación tradicional, actual y pública» en los tres primeros años. La ley ha sido dos veces prorrogada y el nuevo periodo se ha extiendido hasta el año 2017. Según los datos oficiales, a finales de 2013, de un total de 1578 comunidades indígenas en el país sólo 223 (14.13\%) han recibido una resolución oficial que determina las tierras poseídas tradicionalmente. Este ínfimo porcentaje de realización, luego de siete años de tareas, muestra mayor gravedad en las provincias de alta conflictividad por falta de cumplimiento de los derechos indígenas. Ahí donde la ejecución del programa resulta más necesaria y urgente, apenas se han iniciado los trabajos (IWGIA 2014). También disponible en pdf en <http://www.iwgia.org>. 
cian y sensibles por padecer 15 años de desastre ambiental a manos de Repsol». Y presentan bajo el subtítulo «Alternativas al Modelo Extractivista (amenaza a las vidas y territorios indígenas)» lo que para nosotras constituye el ideario del buen vivir entendido como un proyecto político anclado en la afirmación de ser diferentes y querer seguir siéndolo.

El gobierno nacional y el provincial han ya reconocido que se privilegiará la actividad extractiva por sobre las comunidades. [...]. Nosotros tenemos una base poderosa para enfrentar esta amenaza: el Sumak Kawsay o Kume Felen, según la región del país donde vivimos. Lo que se conoce como 'Buen Vivir' o 'Plan de Vida'. Esto se sintetiza en recuperar el proceso de la vida comunitaria ${ }^{20}$ en plenitud, la vida en equilibrio material y espiritual, el equilibrio interno y externo de la comunidad. También en el proceso en que recuperamos una relación permanente con la naturaleza, de armonía con la madre tierra, vivir sin violencia, vivir con afecto y empatía. Es el desafío que como Consejo Plurinacional construimos en nuestro accionar cotidiano. Jallalla - Marici Weu

- Aguyjevete - Yasurupai - Takiñiwe - Muranta !!!

\section{ALGUNAS CONCLUSIONES Y APORTES SOBRE EL IDEARIO DEL VIVIR BIEN EN ARGENTINA}

Desde los pueblos indígenas en la Argentina se han venido demandando otros modelos de vida: incluye reconocimiento de sus identidades, nueva narrativa histórica, autonomía para decidir. Reclamos que se fueron formulando desde la fundación del Estado-nación; muchas veces realizados en forma de reclamos por la propiedad de las tierras, por defensa de los lugares propios; otras en forma de denuncia de la voracidad del sistema productivo occidental que invade y destruye los bosques y contamina los ríos y el suelo; muchas condensan sus demandas en términos ontológicos, cuando se refieren a sus cosmovisiones como sistemas filosófico-ideológicos enfrentados a la civilización. El centro de estas demandas es el reclamo de autonomía y propiedad territorial.

Todas estas demandas han tomado forma jurídica y hoy son derecho vigente en los diferentes Estados, en donde Argentina no es la excepción. Es preciso entonces conjugar miradas diversas para dotar de contenido a nuevas categorías de derechos que fueron surgiendo en el siglo XXI al calor de la gestación de las últimas constituciones latinoamericanas. Así, derechos de la naturaleza o derechos al buen vivir interpelan no solo la concepción clásica del Estado-nación, sino que

${ }^{20}$ R-existencia, según Escobar (2013). 
desafían los actuales modelos de desarrollo, asentados fundamentalmente en las actividades extractivistas.

Será alrededor del cruce de saberes —indígenas y occidentales-y dentro de estos últimos de modo interdisciplinario - a partir de la necesidad de la producción de un diálogo entre el derecho, la antropología, la economía, la ecología, la sociología, etc. - donde se construya un modelo alternativo de desarrollo, revalorizando la perspectiva indígena, para que convivan modos de vida diferentes pero no necesariamente antagónicos.

El debate del último decenio está centrado, precisamente, en estos desafíos, paradojas, antinomias, contradicciones. Los pueblos indígenas van dando forma a sus demandas, enfatizando su propia cosmovisión, que también forma parte de una trama histórica y política. Es deseable y esperable que todos estos elementos vayan consolidándose en mundos profundamente dinámicos, que van dejando lugar progresivamente a espacios de alteridad.

\section{FUENTES DE CONSULTA}

Albo, Xavier, 2014, «Madre Tierra + desarrollo = ¿vivir bien?», diario La Razón, Bolivia, <http://www.la-razon.com/opinion/columnistas/Madre-Tierra-desarrollo-vivirbien_0_2024197696.html> [consulta: 30 de marzo de 2014].

Aranda, Darío, 2013, Derechos originarios: «Somos el otro que sufre», CTA, La agencia de noticias de la Central de Trabajadores de la Argentina (CTA), en <http://www.agenciacta.org/spip.php?article8706> [consulta: 01 de diciembre de 2014].

Briones, Claudia y Morita Carrasco, 2003, «Neoindigenismo estatal y producciones indígenas en Argentina (1985-1999)», Anuário Antropológico 2000-2001, Río de Janeiro, Tempo Brasileiro, pp. 147-167.

Carrasco, Morita, 2000, Los derechos de los pueblos indígenas en Argentina, Buenos Aires, IWGIA / Vinciguerra.

, 2002, «El movimiento indígena anterior a la reforma constitucional y su organización en el Programa de Participación de Pueblos Indígenas», University of Texas, Austin, Teresa Lozano Long Institute of Latin American Studies. <http://lanic.utexas. edu/project/etext/lilas/vrp/carrasco.pdf> [consulta: 1 de diciembre de 2014].

, 2014, «Sentido de la lucha por la propiedad del territorio indígena. Argentina: región del Chaco semiárido», documento preparado para el Segundo Taller Internacional SOGIP «Los Pueblos Indígenas y sus Derechos a la Tierra: Política Agraria y Usos, Conservación, e Industrias Extractivas», 18-21 de junio, París, EHESS/CNRS.

Castoriadis, Cornelius, 1991, «Reflexiones sobre el 'desarrollo' y la 'racionalidad'», en Fernando Viviescas y Fabio Giraldo (comp.), Colombia el despertar de la modernidad, Santa Fe de Bogotá, Foro Nacional por Colombia.

Escobar, Arturo, 2013, «Territorios de diferencia: La ontología política de los «derechos al territorio»», Documento preparado para el Segundo Taller Internacional SOGIP, «Los 
Pueblos Indígenas y sus Derechos a la Tierra: Política Agraria y Usos, Conservación, e Industrias Extractivas», Junio 18-21, París, EHESS/CNRS.

Giarraca, Norma y Miguel Teubal, 2008, «Del desarrollo agroindustrial a la expansión del «agronegocio»: el caso argentino», en Bernardo Mançano Fernándes (comp.), Campesinado y agronegocios en América Latina, Buenos Aires, CLACSO-ASDI.

Greenpeace, 2013, Salta: el festival de desmontes no se detiene, Greenpeace, Argentina, <http://www.greenpeace.org/argentina/Global/argentina/report/2013/bosques/ Informe-Salta-2013-FINAL.pdf> [consulta: 01 de diciembre de 2014].

Gudynas, Eduardo, 2009, «Diez tesis urgentes sobre el nuevo extractivismo. Contextos y demandas bajo el progresismo sudamericano actual», en Extractivismo, política y sociedad, Quito, Centro Andino de Acción Popular (CAAP) / Centro Latino Americano de Ecología Social, pp. 187-225.

, 2010, «La senda biocéntrica: valores intrínseco, derechos de la naturaleza y justicia ecológica», Tabula rasa, 13, pp. 45-71.

,2011, "Caminos para las transiciones post extractivistas», en Alejandra Alayza y Eduardo Gudynas (eds.), Transiciones post extractivismo y alternativas al extractivismo en el Perú, Lima, CEPES, REDGE / CLAES, pp. 187-216.

Harvey, David, 2005, El nuevo imperialismo. Sobre reajustes espacio-temporales y acumulación mediante desposesión, en Revista Herramienta, 29, Buenos Aires.

IWGIA, 2014, El mundo indígena 2014, Santa Cruz, IWGIA.

Ramírez, Silvina, 2012, "Constitucionalismo «Progresista» y Diseños Estatales: Protección vs. Desarrollo», en Julio C. García (coord.), Derecho constitucional indígena, Chaco, Contexto Editorial.

, 2011, «Derechos de los Pueblos indígenas y Derechos de la Naturaleza», Revista Argentina de Teoría Jurídica, 12(2), Argentina, Universidad Torcuato di Tella. Rawls, John, 1979, Teoría de la Justicia, México, Fondo de Cultura Económica.

Sieder, Rachel, 2004, «Del indigenismo institucional integracionista a la gestión pluralista de las políticas pública», IV Congreso de la Red Latinoamericana de Antropología Jurídica, "Globalización y Pluralismo Jurídico: luchas sociales y legales en la construcción de Estados interculturales», agosto, Quito.

Fecha de recepción: 9 de junio de 2014 Fecha de aceptación: 16 de marzo de 2015 